\title{
The impact of major life events on household asset portfolio rebalancing
}

\begin{abstract}
Purpose - Model the asset portfolio rebalancing decisions of Australian households experiencing a severe life event shock.

Design/methodology/approach - Uses household longitudinal data from the Household, Income, and Labour Dynamics in Australia (HILDA) survey since 2001. The major life events are serious illness or injury, death of a spouse, job dismissal or redundancy, and separation from a spouse. The asset classes are bank accounts, cash investments, equities, superannuation (private pensions), life insurance, trust funds, owner-occupied housing, investor housing, business assets, vehicles, and collectibles. We use both static and dynamic Tobit models to assess the impact and duration of impact of the shocks.
\end{abstract}

Findings - Serious illness and injury, loss of employment, separation, and spousal death cause households to rebalance portfolios in ways that can have detrimental effects on long-term wealth accumulation through poor market timing and the incurring of transaction costs.

Research limitations/implications - The survey results are only available since 2001 and the wealth module from which the asset data is drawn is self-reported and not available every year.

Practical implications - Relevant to policymakers working on the ongoing retirement of the 'baby boomer' generation and for financial planners guiding household investment decisions.

Originality/value - Most research on shocks to household wealth concern a narrower range of assets and only limited shocks. Also one of few studies to employ a random effects model to allow for unspecified heterogeneity among households.

Keywords: Household finance, asset portfolios, portfolio rebalancing, life events

Article Classification: Research paper 


\section{Introduction}

Households accumulate wealth to serve several purposes. These include being more financially independent in retirement, to save for asset acquisition, to have a buffer for unexpected expenses, and to be able to bequest wealth to heirs. As asset classes differ in terms of their inherent characteristics, most notably liquidity, it is critical that households hold a mix of assets to serve these different purposes. For example, households will often allocate a portion of their wealth to liquid lower return assets, such as bank accounts, to satisfy precautionary motives for saving and to avoid selling less liquid higher return assets (often with high transaction costs) such as real estate. In essence, the household's portfolio composition will determine how well a household can respond to an event that has financial consequences at short notice and over a longer period. However, as with many areas of household finance, there is little appreciation of precisely how households rearrange their portfolios around and during major life events, things that are often difficult to plan. The availability (albeit limited) of longitudinal panel data suited for this purpose has enhanced our understanding of some household financial decisionmaking dynamics, but there remains much to do.

For the most part, existing international research focuses on labour income shocks. For example, Gomes and Michaelides (2005) concluded that investment in risky assets, including stocks, falls with negative income shocks. Angerer and Lam (2009) also found that a small transitory change (positive or negative) will not induce any portfolio adjustments, whereas a large permanent change will motivate households to either trade down or up assets like the family home to adjust expenditure (i.e. mortgage payments). In some instances, the portfolio rebalancing response is limited to the impact on equities or a specific set of assets like financial/nonfinancial or risky assets, and thus excludes a broader asset portfolio viewpoint. Of course, all of this is overlain by myriad household characteristics that modify the actions and reactions of households to shocks, including openness (Kleine et al., 2016), risk tolerance (Tavor and Garyn-Tal, 2016), the balance of subjective/objective decision-making factors (Becker and Dimpfl, 2016), and the availability of credit (Kukk, 2017).

However, the sources of income shocks other than but also including labour is also of interest. For example, illness and serious injury can have a detrimental impact on the financial circumstances of a household given the loss of income but also increased medical expenses. Those who have investigated health and ageing shocks on household portfolio choice invariably find that a health shock significantly reduces household total financial wealth, in 
turn leading households to restructure their financial assets (Berkowitz and Qui, 2006; Paas et al., 2007; Coile and Milligan, 2009).

It seems obvious, but divorce can also considerably influence wealth accumulation outcomes for households. This is because upon separation, the division of household assets, and the financial constraints faced result in the family home being taken up by one partner or sold (Sheehan and Hughes, 2001). Hendershott et al. (2009) confirmed that divorce has a significant negative impact on net wealth and lowers the probability of home ownership over the longer term. Ulker (2009) and Ong (2009) provide similar findings. Finally, the death of a spouse can inflict economic hardship through loss of income, funeral expenses, lack of estate planning and delays in the time for insurance policies to be processed. In addition, a household may already be under financial stress given the ill health of a spouse before death (Corden et al., 2008). Especially for women, widowhood is associated with a significant decline in the probability of home ownership, and to a lesser degree, ownership of vehicles, businesses and property, and raises the share of assets held in savings accounts (Coile and Miligan, 2009).

The purpose of this paper is to quantify the impact of four major life events on the portfolio shares of eleven asset classes held by Australian households using the Household, Income, and Labour Dynamics in Australia (HILDA) Survey. The HILDA Survey questions respondents annually about whether they have experienced a number of life events, of which we select four for closer examination as we expect that these will pose significant financial consequences for the household. Using the Top-10 Most-Stressful Life Events on the Holmes and Rahe Stress Scale as a guide (Noone, 2017), we select personal injury or illness (53 pts and ranked $6^{\text {th }}$ ), the death of a spouse (100 pts and ranked $1^{\text {st }}$ ), being fired or made redundant (47 pts and ranked $8^{\text {th }}$ ) and separating from a spouse (65 pts and ranked $\left.3^{\text {rd }}\right)$. In addition, every four years the HILDA Survey includes a Wealth Module, which questions households on their overall investment in bank accounts, cash investments, equities, superannuation, life insurance, trust funds, the family home, other property, businesses, vehicles and collectibles. We use this information to assess the changes in asset allocation.

To quantify households' portfolio rebalancing responses to a major life event, we use static longitudinal panel data models to regress each event on the portfolio share of each asset class. We also examine the composition and size of the household portfolios before and after each shock to determine the magnitude and duration of the impact of the life event on financial decisions. To do this, we employ a dynamic model incorporating the lags and leads of each 
shock on the portfolio shares. As discussed, the findings of this research are important as life events (or shocks) may dramatically affect a household's financial position. We are particularly interested in how different shocks impact differently on households, even though they all technically entails shocks to income.

We are also interested in going beyond income and seeing the impact on wealth. Wealth may increase or divide, spending needs change, and new expenditures formed regarding future income, longevity, and bequests. These transitions constitute an important source of risk, with the potential to affect wealth accumulation, including the demand for particular, sometimes risky, assets. This is particularly important to households in seeking to counter what are often high impact but admittedly low probability risks, at least at any particular point of time. Further, over the longer term and in aggregate, the ability of households as a whole to cope with expected and unexpected events has major implications for public policy and calls on the public purse.

The remainder of the paper is organized as follows. Sections 2 and 3 discuss the methodology and data, respectively. Section 4 presents the empirical results. Section 5 concludes.

\section{Data}

We use longitudinal data from the HILDA survey. This survey aims to follow the 7,682 households and 13,969 individuals first interviewed in Wave 1 over time; by 2010, the survey reinterviewed 6,727 households and 13,526 individuals. The range of topics covered by the HILDA Survey include income, labour market and family dynamics, with additional modules added in various years such as the wealth module every four years from 2002 (Wave 2). The wealth module survey questions relate to the householder's assessment of their investment in assets such as bank accounts $(B N K)$, cash investments $(C S H)$, equities $(E Q T)$, superannuation (private pensions) (SPR), cash-in values of life insurance policies (INS), trust funds (TST), the family home $(H O M)$ and other property $(O P R)$, business assets $(B U S)$, vehicles $(V E H)$ and collectibles $(C O L)$. These wealth variables provide the dependent variables used in this study.

\section{$<$ INSERT TABLE I HERE >}

The independent variables mostly pertain to life events experienced by survey respondents. Every wave asks respondents whether they experienced any of 22 listed life events. The life events we hypothesise that will have an impact on the financial circumstances of the household that test their precautionary and other motives for saving and investment include suffering 
serious personal injury/illness $(I N J)$, the death of a spouse $(D T H)$, being fired or made redundant from a job $(F R D)$ and separation from a spouse $(S E P)$. We recode these four life events to match the years a wealth module is included in the household survey. Thus, a respondent received a one if they reported at least one positive response to a shock in the periods 2001-02, 2003-06, and 2007-10.

\section{$<$ INSERT TABLE II HERE>}

Table I details the number of respondents that experienced INJ, DTH, FRD and SEP life events. As shown, there are more instances of respondents experiencing $I N J$, and the number of reported INJ peaked in 2006. Oddly, the reporting of all life events included in this study was highest in 2006. Table II provides further insight into the timing of life events by age. In the original surveys, the categories available are being aged 15-17, 18-19, 20-21, 22-24, 25-34, 35-44, 45-54, 55-64, 65-74 and over 75 years of age. We recoded these into six categories: aged under 24 (AGE1), 25-34 (AGE2), 35-44 (AGE3), 45-54 (AGE4), 55-64 (AGE5) and over 65 (AGE6) years.

\section{$<$ INSERT TABLE III HERE >}

As shown, INJ and FRD peak at AGE4 (45-54 years) Not surprisingly, DTH rises in the AGE6 (over 65 years) category. SEP tends to occur earlier in the life cycle, with SEP highest in the AGE2 (35-44 years) and AGE3 (45-54 years) categories. Because of the importance of age on the likelihood of a life event occurring, all models in the analysis control for household head age. Finally, Table III provides the mean portfolio shares by asset class across the entire sample (i.e. both asset and non-asset holding). As shown, owner-occupied housing and superannuation are the major asset classes for Australian households, accounting for $44.2 \%$ and $20.8 \%$ of all household assets, respectively, followed at some distance by vehicles $(9.1 \%)$, bank accounts $(8.4 \%)$ and other property (7.8\%). The remaining asset classes, including life insurance, trusts, and collectibles, account for only very small shares of household assets overall as few households hold these assets.

\section{Empirical method}

Our primary aim is to measure the impact of selected life events on the asset portfolio shares of Australian households. Further, we aim to measure the magnitude and duration of the impact in terms of the portfolio share of asset classes held before and after a life event. The methodological approach described herein is similar to that used by Coile and Milligan (2009), 
who examined older US households to see whether changes in asset holdings during old age related to health and mortality shocks, including the death of a spouse and events such as a stroke or cancer diagnosis.

The models thus consist of a series of static regressions to model the impact of life events on a household's portfolio share in each asset class. Given the nature of the dependent variable (asset portfolio share, ranging from zero to one), we employ a Tobit model:

$$
y_{i t}=\alpha_{i}+L_{i j t}^{\prime} \beta+\varepsilon_{i t}
$$

where $y_{i t}$ is the asset portfolio share, $L_{i t}$ are a set of life event dummy variables relevant to the household $j, \alpha_{i}$ are random individual-specific effects, and $\varepsilon_{i t}$ is an idiosyncratic error. Note the fixed effects model allows correlation between $\alpha_{i}$ and the regressors $L_{i j t}$, whereas the random effects model assumes that $\alpha_{i}$ is purely random and implies that $\alpha_{i}$ is uncorrelated with the regressors.

The second stage of the analysis is use of a dynamic model to assess the short- and long-term impacts of life events on portfolio composition. We achieve this by including lead and lag dummy variables for each life event in a portfolio share model. This provides a sense of how households respond to each particular type of life event, whether expected or unexpected, in the period leading up to and after the event. Given the long but still limited length of the available data, we can only include two lead and lag variables as follows:

$$
\begin{gathered}
y_{i t}=\beta_{0}+\beta_{1} \text { Lminus } 2+\beta_{2} \text { Lminus } 1+\beta_{3} \text { Lplus } 1+ \\
\beta_{4} \text { Lplus } 2+\beta_{5} \text { age }+\alpha_{\mathrm{i}}+\varepsilon_{\mathrm{it}}
\end{gathered}
$$

We estimate this same model separately for each life event $(L)$ across the portfolio shares of the 11 asset classes.

The expected signs from these regressions are as follows. First, illness and injury may cause ongoing medical expenses and time out of the labour force, causing severe financial hardship and future uncertainty (Lum and Lightfoot, 2003). Similarly, long-term medical conditions may trigger high health care expenditures and divert resources otherwise used for other purposes like retirement, leading to inadequate retirement wealth (Taylor, 2013). Conversely, if one partner in a household has a serious health problem, one or both partners may work longer and save more for retirement as a means of covering higher than average projected household medical expenses. Thus, even though there may be contradictory portfolio rebalancing responses in regards to a health condition, it is predicted that an ongoing illness or 
injury concerns will overall have a negative impact on asset ownership, and cause households to draw down on investment in liquid assets in the short term. Over the longer term, if the condition persists, households may have to draw upon investments in nonfinancial assets, such as property.

Second, the dissolution of an adult couple household has a major impact on the asset ownership of the newly single adult households. Such life events could include the death of a spouse, or divorce/separation. In general, marriage (or de facto relationships) facilitates wealth creation through lowering borrowing constraints because of the combination of the income/wealth of two singletons, economies of scale in consumption, and efficiency gains through the division of labour that increases output and allows couples to save at a greater rate than they would otherwise (Hendershott et al., 2009).

Household dissolution in the form of separation (and ultimately divorce) effectively reverses this wealth effect, as one or both partners move out of their dwelling and divorce settlement involves division of accumulated assets and deadweight losses (legal costs, etc.). In addition, there are expenses incurred to set up new dwellings and child custody arrangements can restrict the labour supply of the primary carer. While individuals may attempt to maintain consumption at a pre-divorce level, and only gradually readjust over time to the revised income level, they are also more likely to prefer rental accommodation as they feel they are in a transitional phase and unable to make long-term commitments (Hendershott et al., 2009). Therefore we hypothesise that separation will negatively affect net wealth, and that households may divest many assets, including the family home as an immediate portfolio rebalancing response to these events.

Third, the same logic applies to widows and widowers, in that in the exception of an insurance payout, the surviving household member will suffer wealth losses due to the loss of income, economies of scale, and efficiency gains upon the death of a spouse. However, in this case, we hypothesise that these households do not sell their family homes as an immediate portfolio rebalancing response. This is because the lower (single-person) pension payments and higher accommodation costs associated with renting or moving are disincentives in Australia to selling the family home as it may push household income below the poverty line. Further, while the bequest of the family home is a longstanding cultural practice in Australia, this desire to bequest wealth to the next generation seems to be significantly diminishing (Olsberg and Winters, 2005). However, the widow/widower may divest many other assets, especially when held in 
the deceased spouse's name, as a means to fund consumption. This hypothesis differs from that of Coile and Milligan (2009), who found in the US context that the death of a spouse was a significant and strong predictor of selling the principal residence, and increases in liquid assets and savings accounts.

Fourth, studies on unexpected job loss, including dismissal and redundancy, find that it affects households through multiple channels, including financial stress from the negative income shock and psychological shocks associated with a decline in individual self-esteem and perceived role in society (Mendolia, 2009). We presume that given the financial stress of potential job loss, a household will follow a precautionary savings motive and save liquid assets for such unexpected life events (Poterba and Samwick, 1997). However, empirical studies show that households may also use less liquid assets (including housing) to satisfy the precautionary savings motive (Carroll et al., 2003). Nonetheless, we hypothesise that job loss causes households to divest liquid assets in the short run, but that if joblessness (and related psychological issues) persist, they will then divest of less liquid assets.

\section{Empirical results}

Table IV presents the estimated coefficients, standard errors and p-values of the random effects Tobit regression for the static analysis. Wald tests indicate that the specified models outperform a constant-only specification for all models except TST (trusts) and COL (collectibles), so we omit the latter from further discussion. This is likely because no more than $1 \%$ of the sample households hold these assets.

\section{$<$ INSERT TABLE IV HERE $>$}

As shown, the event that provides the largest positive impact by far on an asset class is $D T H$ (death of a spouse) on $B N K(0.136)$ (bank accounts). Thus, the death of a spouse may result in a positive cash gain due to insurance or other payout, including the spouse's superannuation or unpaid work entitlements. DTH also has a small positive impact on the portfolio share of $L F I$ (0.012) (life insurance) and EQT (0.009) (equity), perhaps indicating that a small portion of any cash windfall is directed into life insurance and/or share market investment. Because of the increased portfolio share to these asset classes, the main reduction in portfolio share is for $\operatorname{SPR}(-0.040)$ (superannuation).

The next largest positive impact is that of SEP (separation) on SPR (0.037). SEP also positively influences $B N K(0.026)$ and $V E H(0.024)$ (vehicles), and these positive impacts are most likely 
attributed to the reduced portfolio shares of HOM (-0.079) (family home) and BUS (-0.011) (business). These results highlight the division of assets that occur after a marriage breakdown, selling off the family home and family-run businesses. Consequently, the portfolio share of $B N K, V E H$ and $S P R$ play a more dominant role in the portfolio.

The liquid nature of $B N K$ and $E Q T$ is especially clear for individuals that experience $I N J$ (illness/injury) and $F R D$ (fired or made redundant). For $F R D$, there is a reduction in both the portfolio shares of $B N K(-0.010)$ and $E Q T(-0.006)$, while the portfolio share of $S P R$ increases (0.027). For $I N J$, there are reductions in the portfolio share of $B N K(-0.009), E Q T(-0.003)$ and $B U S$ (-0.005), which are offset by the positive increase to the portfolio share of both types of real estate (property), HOM (0.007) and OPR (0.010). It seems likely that households draw on liquid assets in these circumstances to cover increased expenses and/or reductions in income.

These results highlight some important findings. First, the portfolio share of home ownership represents only a significant reduction for $S E P$, which is expected and largely unavoidable for many households experiencing the dissolution of a marriage/partnership with the division of matrimonial/shared assets. We do not find that the other events (INJ, DTH and FRD), where the capacity to continue to make mortgage payments or otherwise maintain a house may also be jeopardised, negatively affect the overall portfolio share of HOM. Second, on the whole, $D T H$ seems to impact positively on the portfolio share of assets used for savings purposes like $B N K, E Q T$ and LFI. Lastly, we find that only two life events, INJ and FRD, draw down on liquid assets like $B N K$ and $E Q T$, most likely as a means to smooth consumption.

\section{<INSERT TABLE V HERE>}

In the next part of the analysis, we undertake the dynamic analysis of asset shares. However, in the interests of brevity, we do not do this for CSH, LFI, TST, BUS and COL as they represent only very small asset shares for all households (see Table III). Table V presents the dynamic analysis findings for $B N K, E Q T$ and $S P R$. For the portfolio share of $B N K$, the significant coefficients indicate that there are generally small increases in anticipation of and in response to life events. For example, two periods prior to a life event occurring, there is a 1.7 percentage point increase in anticipation of INJ and a 1.7 percentage point increase for SEP. One period prior, there is a 1.0 percentage point increase for $F R D$. In one period after the life event was experienced, there is an increase for $I N J(0.017)$ and $D T H(0.037)$, and two periods after there is an increase of 7.6 percentage points for $S E P(0.017)$. For all life events examined, $B N K$ 
attracts positive portfolio rebalancing responses given both the near universal role it plays as a basic savings product.

For $E Q T$, households engage in a consistent portfolio rebalancing response within the asset portfolio across the range of life events. In both periods leading up to the life event occurring, there are incremental increases to the portfolio share of EQT for those households that experienced INJ (Shock-2, 0.010; Shock-1, 0.009). After the life event has occurred, there are sustained but small reductions in the portfolio share of $E Q T$ when a household experiences $I N J$ $(-0.006), D T H(-0.017)$, and SEP (-0.014), but there is a pattern of longer-term portfolio restructurings that occur for all life events: INJ $(-0.011), D T H(-0.034), F R D(-0.013)$ and SEP (-0.016). The largest of these decreases is for DTH and is for Shock+2, which decreases by a relative 85 percent of the mean portfolio share of 4 percent. These results are indicative of the liquid nature of equities and the capacity of shares to provide a higher potential rate of return for investors. However, a small component of the results could be representative of the aftermath of the GFC in that people exited the stock market because of increased uncertainty or the decline in share market values.

The role of $S P R$ in household portfolios is interesting because its compulsory nature (in Australia) means that households cannot draw upon it except in retirement (unless there are grounds for compassionate or severe financial hardship, and then only in a limited way). Its then most likely for changes to the portfolio share of $S P R$ to result from the rebalancing of the shares of other asset classes. Table V shows that in the lead up to the life event occurring, there is generally a reduction of the portfolio share of SPR. For FRD (-0.017) and SEP (-0.049) there were incremental decreases in Shock-2, and for INJ (-0.005), DTH (-0.021) and SEP (-0.025) there are incremental decreases in Shock-1. After the shock, there are short-term portfolio adjustments that result in slight increases in the portfolio share of SPR for INJ (0.014), FRD (0.030) and SEP (0.038), and longer-term adjustment increases for INJ (0.020), DTH (0.076) and SEP (0.022). The largest of these increases is for $D T H$, which is a 36.5 percent relative increase from the mean portfolio share rate up to eight years after the event. This is at odds with the findings of the previous section that pointed to an overall decrease in the portfolio share of $S P R$ when $D T H$ was experienced.

\section{$<$ INSERT TABLE VI HERE $>$}

Table VI presents the dynamic model results for $H O M, O P R$ and $V E H$. The portfolio rebalancing before and after a $S E P$ for $H O M$ is of some interest. In both periods leading up to 
SEP, HOM has an increased portfolio share (Shock-2, 0.038; Shock-1, 0.015). Upon SEP, there is an immediate reduction in the portfolio share of HOM $(-0.033)$, but over the longer term the portfolio share is increased by about the same amount. Thus, individuals that have previously owned a home are likely to return to home ownership in the long term, perhaps to accommodate the needs of children and/or derive utility from the multiple benefits home ownership provides. A portfolio increase in home ownership also occurs with households that have experienced FRD two periods beforehand (0.020). Decreases in portfolio share occur two periods before INJ occurs (-0.010), and one period before DTH occurs (-0.030). Those that experience an INJ rebalance their portfolio to increase the portfolio share of $H O M$ one period after $(0.010)$.

For $O P R$, the patterns in the portfolio share reveal that generally households have a lower portfolio share of $O P R$ in both the short and long-term before a life event occurs. For example, the largest reduction in the portfolio share of $O P R$ occurs for $F R D$, where a reduction of -0.037 occurs in Shock-2, and -0.017 in Shock-1. Those that have experienced a SEP reduce the portfolio share of $O P R$ by -0.023 in Shock-2, and -0.012 in Shock-1. For INJ, the reductions are -0.020 in Shock-2 and -0.008 in Shock-1. The only positive rebalancing occurs after experiencing FRD, in Shock+1 (0.016) and Shock+2 (0.021). There are no significant coefficients for $D T H$.

Lastly, we may generally may attribute the changes in the portfolio share of $V E H$ to the rebalancing of other assets, or an upgrading of motor vehicles held by the household. The results in Table VI show that there is a consistent increase in the portfolio share of $V E H$ before a life event occurs, and this applies for households that experience any of the life events in the period immediately prior. The highest relative increase is for $D T H$, where there is a 40.7 percent increase relative to the mean portfolio share of 9.1 percent in the period immediately prior. Afterwards, there is a short-term decrease in the portfolio share of $V E H$ when a household experiences $F R D$, and in the long term if $D T H$ is experienced (we think because of the disposal of the unneeded vehicle in two-vehicle households).

In brief, the findings of the dynamic Tobit models confirm that households sometimes make portfolio-rebalancing decisions for precautionary reasons in anticipation of a life event occurring, and increase portfolio shares in $B N K, E Q T$, and $V E H$. After a life event occurs, we typically observe reduced portfolio shares for $E Q T$ and $V E H$. Especially for $E Q T$, these results are highly suggestive of their liquid nature. Also of note is the role of HOM in portfolios where 
a SEP occurs in that although SEP results in a decrease in the portfolio share immediately after, over the long term HOM returns to an increased role in the asset portfolio.

In addition, our relatively simple models in Tables V and VI do a remarkably good job of explaining the variation in asset shares in terms of the Cox-Snell $\mathrm{R}^{2}$. For the six most-widely and majorly held asset classes in Australia, our models explain on average $72 \%$ of the variation in $B N K, 94 \%$ in EQT, $40 \%$ in $S P R, 50 \%$ in $H O M, 66 \%$ in $O P R$ and $73 \%$ in $V E H$. This suggests that models just including age and the incidence of major life events best explain restructuring into and from very liquid assets (including $B N K, E Q T$ and $V E H$ ) and not much less liquid assets (like $S P R$ ). On this basis, we argue that liquidity is the primary asset feature considered by households in restructuring their portfolios before and after major life events. There is also a notable difference between how well the models explain the asset restructuring for $H O M$ vs. $O P R$, clearly linked with the fact that the family home, unlike investor property, has both investment and consumption characteristics.

\section{Conclusion}

We aimed to provide insight into the impact of life events on the broad asset portfolio decisions of Australian households. Specifically, we investigated how life events affected portfolio shares across a range of asset classes, and measured household responses before and after major life events, being serious illness or injury (INJ), death of a spouse $(D T H)$, been fired or made redundant $(F R D)$ and separation from a spouse $(S E P)$. This research is important as life events (and the income and other shocks associated with them) such as these may dramatically affect a household's current and future financial position. Wealth may increase or decrease, spending needs change, and new expenditures formed affecting future income, longevity, and bequests. These transitions constitute an important source of risk, with the potential to affect wealth accumulation, including the demand for (risky but higher return) assets.

The analysis provides a number of important contributions. First, there is limited research to date on shocks to household income and wealth, not least in Australia, and these tend to focus on a very narrow range of assets (i.e. equities) and a limited array of shocks (health, labour income). We thereby include a broader range of asset classes and a wider range of shocks. Further, this is the first study of its kind utilising Australian panel data, and we extend the novel approach in Coile and Milligan (2009) previously used in the US to employ a random effects model rather than a fixed effects model to allow for the many expected but unspecified differences between households to exert some influence on the dependent variables. 
Our results confirm the proposition that major life events generally influence the asset portfolios of households, both before and after a significant event. The Tobit models of these impacts highlighted circumstances where households may be more financially vulnerable in terms of wealth accumulation due to reducing the portfolio share of assets in response to a life event. These circumstances include reducing the portfolio share of EQT in response to experiencing $I N J$ and $F R D$, or $H O M$ in response to $S E P$. While insurance products for injury, illness, and redundancy may assist households to manage the costs of these life events, there is no comparable financial product for $S E P$.

We obtained some finer detail on the financial decisions made by households was using dynamic Tobit models incorporating lead and lag variables. The long-term divestment of $E Q T$ following all life events is a major cause of concern for household wealth accumulation, above all because over the entire period over which the HILDA Survey has been conducted, equity investment has outperformed all other asset classes, with the possible exception of owneroccupied property. While the reduced portfolio share may be a reflection of the GFC and attitudes towards the stock market following the large reductions in share market value in 2008, over the 2006 to 2010 period (i.e. Shock+1 and Shock+2) the Australian stock market still averaged a quite reasonable 10.16 percent return. Another significant finding was that households that experience a $S E P$ return to HOM in the long term, which may have transaction cost implications on the household in terms of agent commissions when the family home sold and stamp duty for new home purchase.

These findings are particularly relevant to public policy makers as they work to on the ongoing retirement of the 'baby boomer' generation and for financial planners in general who incorporate expected future performance of asset markets into their investment decisions. Specifically, financial planners need to ensure that clients have a diverse range of liquid assets or insurance products that are able to assist with smoothing consumption when required, particularly in the case of an unforeseen event, and thence are able to avoid fire sales.

\section{References}

Angerer, X. and Lam, P-S. (2009), "Income risk and portfolio choice: an empirical study", Journal of Finance, Vol. 64 No. 2, pp. 1037-1055.

Becker, G. and Dimpfl, T. (2016), "Labor income risk and households' risky asset holdings", Studies in Economics and Finance, Vol. 33 No. 2, pp. 262-280.

Berkowitz, M.K. and Qiu, J. (2006), "A further look at household portfolio choice and health status", Journal of Banking and Finance, Vol. 30 No. 4, pp. 1201-1217. 
Carroll, C.D., Dynan, K.E. and Krane, S.D. (2003), "Unemployment risk and precautionary wealth: evidence from households' balance sheets", Review of Economics and Statistics, Vol. 85 No. 3, pp. 586-604.

Coile, C. and Milligan, K. (2009), "How household portfolios evolve after retirement: the effect of aging and health shocks", Review of Income and Wealth, Vol. 55 No. 2, pp. 226-248.

Corden, A., Hirst, M. and Nice, K. (2008), Financial Implications of Death of a Partner. Working Paper No. ESRC 2288 12.08. Social Policy Research Unit, University of York.

Gomes, F. and Michaelides, A. (2005). Optimal life-cycle asset allocation: understanding the empirical evidence", Journal of Finance, Vol. 60 No. 2, pp. 869-904.

Hendershott, P., Ong, R., Wood, G. and Flatau, P. (2009), "Marital history and home ownership: evidence from Australia", Journal of Housing Economics, Vol. 18 No. 1, pp. 13-24.

Kleine, J., Wagner, N. and Weller, T. (2016) "Openness endangers your wealth: noise trading and the Big Five", Finance Research Letters, Vol. 16, pp. 239-247.

Kukk, M. (2017), "How does household debt affect financial asset holdings? Evidence from euro area countries", Studies in Economics and Finance, Vol. 34 No. 2, pp. 194-212.

Lum, Y-S. and Lightfoot, E. (2003), “The effect of health on retirement saving among older workers', Social Work Research, Vol. 27 No. 1, pp. 31-44.

Mendolia, S. (2009), The Impact of Job Loss on Mental Health. CAER Workshop on Health Economics. University of NSW.

Noone, P.A. (2017), “The Holmes-Rahe stress inventory”, Occupational Medicine, Vol. 67 No. 7, pp. 581-582.

Olsberg, D. and Winters, M. (2005), Ageing in Place: Intergenerational and Intrafamilial Housing Transfers and Shifts in Later Life, AHURI Final Report No. 88, Australian Housing and Urban Research Institute Limited, Melbourne.

Ong, R. (2009), "Self-provision in retirement: quantitative evidence on older Australians' expectations and experiences", Australian Journal of Ageing, Vol. 26 No. 1, pp. 22-27.

Paas, L.J., Bijmolt, T.H.A. and Vermunt, J.K. (2007), "Acquisition patterns of financial products: a longitudinal investigation”, Journal of Economic Psychology, Vol. 28 No. 2, pp. 229-241.

Poterba, J.M. and Samwick, A. (1997), Household Portfolio Allocation over the Life Cycle, National Bureau of Economic Research Working Paper No. 6185, Cambridge, MA.

Sheehan, G. and Hughes, J. (2001), Division of matrimonial property in Australia. Australian Institute of Family Studies, Vol. 25, pp. 1-39.

Tavor, T. and Garyn-Tal, S. (2016), "Risk tolerance and rationality in the case of retirement savings", Studies in Economics and Finance, Vol. 33 No. 4, pp. 688-703.

Taylor, L.B. (2013), In Sickness or in Health: Couples' Health Status and Retirement Preparation, Master of Science in Human Development and Social Policy, University of Utah, Utah.

Ulker, A. (2009), "Wealth holdings and portfolio allocation of the elderly: the role of marital history", Journal of Family and Economic Issues, Vol. 30 No. 1, pp. 90-108. 
Table I.

Sample incidence

of life events

\begin{tabular}{lrrrrrrr}
\hline \multirow{2}{*}{ Life event } & \multicolumn{2}{c}{2002} & \multicolumn{2}{c}{2006} & \multicolumn{2}{c}{2010} & \multirow{2}{*}{ Total } \\
& \multicolumn{1}{c}{ No. } & \multicolumn{1}{c}{$\%$} & \multicolumn{1}{c}{ No. } & \multicolumn{1}{c}{$\%$} & \multicolumn{1}{c}{ No. } & \multicolumn{1}{c}{$\%$} & \\
\hline INJ & 1,270 & 18.1 & 2,981 & 43.5 & 2,727 & 39.9 & 6,979 \\
DTH & 65 & 0.9 & 185 & 2.7 & 171 & 2.5 & 421 \\
FRD & 250 & 3.6 & 552 & 8.0 & 536 & 7.8 & 1,338 \\
SEP & 275 & 3.9 & 648 & 9.4 & 547 & 8.0 & 1,470 \\
\hline Total events & 1,860 & 26.5 & 4,366 & 60.9 & 3,981 & 58.2 & 10,208 \\
Total households & 7,002 & - & 6,860 & - & 6,840 & - & 20,702 \\
\hline
\end{tabular}

Table II.

Percentage of respondents by age experiencing life event, all years

\begin{tabular}{ccrrrr}
\hline Variable & $\begin{array}{c}\text { Age in } \\
\text { years }\end{array}$ & \multicolumn{1}{c}{ INJ } & \multicolumn{1}{l}{ DTH } & FRD & SEP \\
\hline AGE1 & $<24$ & 2.30 & 0.00 & 0.90 & 1.10 \\
AGE2 & $25-34$ & 5.70 & 0.30 & 1.70 & 2.40 \\
AGE3 & $35-44$ & 10.60 & 0.30 & 2.00 & 2.60 \\
AGE4 & $45-54$ & 12.50 & 0.30 & 2.20 & 2.00 \\
AGE5 & $55-64$ & 9.80 & 0.50 & 1.10 & 0.90 \\
AGE6 & $>65$ & 9.10 & 1.20 & 0.30 & 0.50 \\
\hline
\end{tabular}

Table III.

Percentage mean portfolio shares, all respondents

\begin{tabular}{ccccccccccc}
\hline BNK & CSH & EQT & SPR & LFI & TST & HOM & OPR & BUS & VEH & COL \\
\hline 8.4 & 0.3 & 4.0 & 20.8 & 0.9 & 0.4 & 44.2 & 7.8 & 3.2 & 9.1 & 1.0 \\
\hline
\end{tabular}


Table IV.

Estimated static models for all portfolio shares

\begin{tabular}{|c|c|c|c|c|c|c|c|c|c|c|c|c|}
\hline Variable & Statistic & BNK & $\mathrm{CSH}$ & EQT & SPR & LFI & TST & HOM & OPR & BUS & VEH & $\mathrm{COL}$ \\
\hline \multirow[t]{3}{*}{ AGE } & Coef. & 0.001 & 0.002 & 0.001 & -0.003 & $<0.001$ & $<0.001$ & 0.003 & -0.002 & $<0.001$ & -0.002 & $<0.001$ \\
\hline & Std. err. & $<0.001$ & $<0.001$ & $<0.001$ & $<0.001$ & $<0.001$ & $<0.001$ & $<0.001$ & $<0.001$ & $<0.001$ & $<0.001$ & $<0.001$ \\
\hline & p-value & $<0.001$ & $<0.001$ & $<0.001$ & $<0.001$ & $<0.001$ & 0.588 & $<0.001$ & 0.012 & $<0.001$ & $<0.001$ & 0.965 \\
\hline \multirow[t]{3}{*}{ INJ } & Coef. & -0.009 & $<0.001$ & -0.003 & 0.001 & $<0.001$ & 0.001 & 0.007 & 0.010 & -0.005 & -0.002 & $<0.001$ \\
\hline & Std. err. & 0.002 & 0.004 & 0.001 & 0.003 & 0.001 & 0.001 & 0.004 & 0.002 & 0.002 & 0.002 & 0.001 \\
\hline & p-value & $<0.001$ & 0.324 & 0.028 & 0.695 & 0.940 & 0.212 & 0.057 & $<0.001$ & 0.002 & 0.400 & 0.940 \\
\hline \multirow[t]{3}{*}{ DTH } & Coef. & 0.136 & -0.001 & 0.009 & -0.040 & 0.012 & $<0.001$ & 0.021 & -0.010 & -0.003 & 0.009 & -0.005 \\
\hline & Std. err. & 0.007 & 0.001 & 0.004 & 0.009 & 0.003 & 0.002 & 0.013 & 0.008 & 0.005 & 0.007 & 0.003 \\
\hline & p-value & 0.053 & 0.289 & 0.046 & 0.001 & $<0.001$ & 0.867 & 0.096 & 0.190 & 0.563 & 0.176 & 0.090 \\
\hline \multirow[t]{3}{*}{ FRD } & Coef. & -0.010 & 0.001 & -0.006 & 0.027 & -0.002 & -0.001 & -0.012 & $<0.001$ & -0.005 & 0.004 & 0.001 \\
\hline & Std. err. & 0.004 & 0.001 & 0.003 & 0.005 & 0.002 & 0.001 & 0.007 & 0.005 & 0.003 & 0.004 & 0.002 \\
\hline & p-value & 0.022 & 0.526 & 0.022 & $<0.001$ & 0.131 & 0.280 & 0.119 & 0.968 & 0.103 & 0.277 & 0.582 \\
\hline \multirow[t]{3}{*}{ SEP } & Coef. & 0.026 & $<0.001$ & -0.399 & 0.037 & -0.002 & $<0.001$ & -0.079 & 0.006 & -0.011 & 0.024 & 0.003 \\
\hline & Std. err. & 0.004 & 0.008 & 0.003 & 0.005 & 0.001 & 0.001 & 0.007 & 0.005 & 0.003 & 0.004 & 0.002 \\
\hline & p-value & $<0.001$ & 0.930 & 0.117 & 0.001 & 0.174 & 0.683 & $<0.001$ & 0.190 & $<0.001$ & $<0.001$ & 0.106 \\
\hline \multirow[t]{3}{*}{ CONS } & Coef. & 0.015 & -0.005 & -0.002 & 0.335 & 0.018 & 0.005 & 0.289 & 0.086 & 0.058 & 0.189 & 0.009 \\
\hline & Std. err. & 0.005 & 0.001 & 0.003 & 0.007 & 0.001 & 0.001 & 0.010 & 0.005 & 0.003 & 0.005 & 0.002 \\
\hline & p-value & 0.004 & $<0.001$ & 0.515 & $<0.001$ & $<0.001$ & $<0.001$ & $<0.001$ & $<0.001$ & $<0.001$ & $<0.001$ & $<0.001$ \\
\hline \multirow[t]{2}{*}{ Wald $\chi^{2}$} & Stat. & 252.590 & 120.730 & 254.250 & 566.400 & 73.590 & 2.930 & 468.390 & 26.530 & 82.560 & 526.960 & 5.710 \\
\hline & p-value & $<0.001$ & $<0.001$ & $<0.001$ & $<0.001$ & $<0.001$ & 0.711 & $<0.001$ & $<0.001$ & $<0.001$ & $<0.001$ & 0.335 \\
\hline
\end{tabular}


Table V.

Estimated dynamic models for portfolio shares of $B N K, E Q T$ and $S P R$

\begin{tabular}{|c|c|c|c|c|c|c|c|c|c|c|c|c|c|}
\hline \multirow{2}{*}{ Variable } & \multirow{2}{*}{ Statistic } & \multicolumn{4}{|c|}{ BNK } & \multicolumn{4}{|c|}{ EQT } & \multicolumn{4}{|c|}{ SPR } \\
\hline & & INJ & DTH & FRD & SEP & INJ & DTH & FRD & SEP & INJ & DTH & FRD & SEP \\
\hline \multirow[t]{3}{*}{ AGE } & Coef. & 0.001 & 0.001 & 0.001 & 0.001 & 0.001 & 0.001 & 0.001 & 0.001 & -0.003 & -0.003 & -0.003 & -0.003 \\
\hline & Std. err. & $<0.001$ & $<0.001$ & $<0.001$ & $<0.001$ & $<0.001$ & $<0.001$ & $<0.001$ & $<0.001$ & $<0.001$ & $<0.001$ & $<0.001$ & $<0.001$ \\
\hline & p-value & $<0.001$ & $<0.001$ & $<0.001$ & $<0.001$ & $<0.001$ & $<0.001$ & $<0.001$ & $<0.001$ & $<0.001$ & $<0.001$ & $<0.001$ & $<0.001$ \\
\hline \multirow[t]{3}{*}{ Shock+2 } & Coef. & -0.002 & 0.030 & -0.003 & 0.017 & -0.011 & -0.034 & -0.013 & -0.016 & 0.020 & 0.076 & 0.013 & 0.022 \\
\hline & Std. err. & 0.010 & 0.019 & 0.010 & 0.007 & 0.003 & 0.012 & 0.006 & 0.006 & 0.006 & 0.024 & 0.012 & 0.012 \\
\hline & p-value & 0.840 & 0.117 & 0.760 & 0.018 & $<0.001$ & 0.004 & 0.034 & 0.007 & $<0.001$ & 0.002 & 0.286 & 0.072 \\
\hline \multirow[t]{3}{*}{ Shock+1 } & Coef. & 0.017 & 0.037 & -0.008 & -0.002 & -0.006 & -0.017 & -0.001 & -0.014 & 0.014 & -0.017 & 0.030 & 0.038 \\
\hline & Std. err. & 0.007 & 0.014 & 0.007 & 0.010 & 0.002 & 0.009 & 0.005 & 0.004 & 0.004 & 0.018 & 0.009 & 0.009 \\
\hline & $\mathrm{p}$-value & 0.018 & 0.008 & 0.301 & 0.840 & 0.005 & 0.046 & 0.902 & 0.002 & 0.001 & 0.343 & 0.001 & $<0.001$ \\
\hline \multirow[t]{3}{*}{ Shock-1 } & Coef. & 0.007 & -0.008 & 0.010 & 0.007 & 0.009 & -0.002 & 0.002 & -0.003 & -0.005 & -0.021 & -0.004 & -0.025 \\
\hline & Std. err. & 0.005 & 0.008 & 0.005 & 0.005 & 0.001 & 0.005 & 0.003 & 0.003 & 0.003 & 0.010 & 0.006 & 0.006 \\
\hline & $\mathrm{p}$-value & 0.106 & 0.284 & 0.027 & 0.106 & $<0.001$ & 0.652 & 0.573 & 0.293 & 0.093 & 0.032 & 0.488 & $<0.001$ \\
\hline \multirow[t]{3}{*}{ Shock-2 } & Coef. & 0.017 & 0.013 & 0.001 & 0.017 & 0.010 & 0.003 & 0.005 & 0.004 & -0.004 & -0.003 & -0.017 & -0.049 \\
\hline & Std. err. & 0.007 & 0.012 & 0.007 & 0.007 & 0.002 & 0.007 & 0.004 & 0.004 & 0.004 & 0.015 & 0.008 & 0.008 \\
\hline & p-value & 0.011 & 0.266 & 0.828 & 0.011 & $<0.001$ & 0.658 & 0.222 & 0.355 & 0.298 & 0.854 & 0.047 & $<0.001$ \\
\hline \multirow[t]{3}{*}{ CONS } & Coef. & 0.012 & 0.017 & 0.014 & 0.012 & -0.013 & -0.004 & -0.005 & -0.003 & 0.352 & 0.345 & 0.346 & 0.354 \\
\hline & Std. err. & 0.005 & 0.005 & 0.005 & 0.005 & 0.003 & 0.003 & 0.003 & 0.003 & 0.007 & 0.007 & 0.007 & 0.007 \\
\hline & $\mathrm{p}$-value & 0.018 & 0.001 & 0.006 & 0.018 & $<0.001$ & 0.181 & 0.140 & 0.315 & $<0.001$ & $<0.001$ & $<0.001$ & $<0.001$ \\
\hline \multirow[t]{2}{*}{ Wald $\chi^{2}$} & Stat. & 197.920 & 198.720 & 193.830 & 200.690 & 364.550 & 246.560 & 242.960 & 252.470 & 497.890 & 480.100 & 479.360 & 548.860 \\
\hline & p-value & $<0.001$ & $<0.001$ & $<0.001$ & $<0.001$ & $<0.001$ & $<0.001$ & $<0.001$ & $<0.001$ & $<0.001$ & $<0.001$ & $<0.001$ & $<0.001$ \\
\hline $\mathrm{R}^{2}$ & & 0.720 & 0.720 & 0.720 & 0.721 & 0.935 & 0.935 & 0.935 & 0.935 & 0.400 & 0.399 & 0.399 & 0.401 \\
\hline
\end{tabular}


Table VI.

Estimated dynamic models for portfolio shares of

$H O M, O P R$ and VEH

\begin{tabular}{|c|c|c|c|c|c|c|c|c|c|c|c|c|c|}
\hline \multirow{2}{*}{ Variable } & \multirow{2}{*}{ Statistic } & \multicolumn{4}{|c|}{$\mathrm{HOM}$} & \multicolumn{4}{|c|}{ OPR } & \multicolumn{4}{|c|}{ VEH } \\
\hline & & INJ & DTH & FRD & SEP & INJ & DTH & FRD & SEP & INJ & DTH & FRD & SEP \\
\hline \multirow[t]{3}{*}{ AGE } & Coef. & 0.003 & 0.003 & 0.003 & 0.004 & $<0.001$ & $<0.001$ & $<0.001$ & $<0.001$ & -0.002 & -0.002 & -0.002 & -0.002 \\
\hline & Std. err. & $<0.001$ & $<0.001$ & $<0.001$ & $<0.001$ & $<0.001$ & $<0.001$ & $<0.001$ & $<0.001$ & $<0.001$ & $<0.001$ & $<0.001$ & $<0.001$ \\
\hline & p-value & $<0.001$ & $<0.001$ & $<0.001$ & $<0.001$ & $<0.001$ & 0.017 & 0.001 & 0.003 & $<0.001$ & $<0.001$ & $<0.001$ & $<0.001$ \\
\hline \multirow[t]{3}{*}{ Shock+2 } & Coef. & -0.004 & -0.048 & -0.011 & 0.030 & 0.004 & 0.031 & 0.021 & -0.007 & -0.004 & -0.035 & -0.011 & -0.004 \\
\hline & Std. err. & 0.008 & 0.034 & 0.018 & 0.017 & 0.005 & 0.021 & 0.011 & 0.011 & 0.004 & 0.019 & 0.010 & 0.010 \\
\hline & p-value & 0.606 & 0.161 & 0.535 & 0.086 & 0.447 & 0.144 & 0.056 & 0.550 & 0.394 & 0.066 & 0.275 & 0.676 \\
\hline \multirow[t]{3}{*}{ Shock+1 } & Coef. & 0.010 & -0.001 & -0.015 & -0.033 & $<0.001$ & -0.010 & 0.016 & 0.001 & -0.005 & 0.020 & -0.015 & 0.005 \\
\hline & Std. err. & 0.006 & 0.025 & 0.013 & 0.013 & 0.004 & 0.016 & 0.008 & 0.008 & 0.003 & 0.014 & 0.007 & 0.007 \\
\hline & p-value & 0.085 & 0.984 & 0.261 & 0.010 & 0.925 & 0.536 & 0.050 & 0.907 & 0.119 & 0.142 & 0.042 & 0.508 \\
\hline \multirow[t]{3}{*}{ Shock-1 } & Coef. & -0.007 & -0.030 & 0.008 & 0.015 & -0.008 & 0.013 & -0.017 & -0.012 & 0.007 & 0.037 & 0.011 & 0.020 \\
\hline & Std. err. & 0.004 & 0.014 & 0.008 & 0.008 & 0.003 & 0.009 & 0.005 & 0.005 & 0.002 & 0.008 & 0.005 & 0.005 \\
\hline & p-value & 0.114 & 0.034 & 0.345 & 0.073 & 0.003 & 0.157 & 0.002 & 0.022 & 0.003 & $<0.001$ & 0.022 & $<0.001$ \\
\hline \multirow[t]{3}{*}{ Shock-2 } & Coef. & -0.010 & -0.023 & 0.020 & 0.038 & -0.020 & -0.019 & -0.037 & -0.023 & 0.004 & 0.031 & 0.021 & 0.024 \\
\hline & Std. err. & 0.005 & 0.021 & 0.012 & 0.012 & 0.003 & 0.013 & 0.007 & 0.007 & 0.003 & 0.012 & 0.007 & 0.006 \\
\hline & p-value & 0.064 & 0.278 & 0.092 & 0.001 & $<0.001$ & 0.156 & $<0.001$ & 0.002 & 0.153 & 0.007 & 0.001 & $<0.001$ \\
\hline \multirow[t]{3}{*}{ CONS } & Coef. & 0.287 & 0.278 & 0.274 & 0.271 & 0.098 & 0.089 & 0.094 & 0.093 & 0.187 & 0.192 & 0.189 & 0.186 \\
\hline & Std. err. & 0.010 & 0.010 & 0.010 & 0.010 & 0.005 & 0.005 & 0.005 & 0.005 & 0.005 & 0.005 & 0.005 & 0.005 \\
\hline & p-value & $<0.001$ & $<0.001$ & $<0.001$ & $<0.001$ & $<0.001$ & $<0.001$ & $<0.001$ & $<0.001$ & $<0.001$ & $<0.001$ & $<0.001$ & $<0.001$ \\
\hline \multirow[t]{2}{*}{ Wald $\chi^{2}$} & Stat. & 351.300 & 345.680 & 344.270 & 366.560 & 56.320 & 12.890 & 48.970 & 21.130 & 505.440 & 519.030 & 507.600 & 520.590 \\
\hline & p-value & $<0.001$ & $<0.001$ & $<0.001$ & $<0.001$ & $<0.001$ & 0.025 & $<0.001$ & 0.001 & $<0.001$ & $<0.001$ & $<0.001$ & $<0.001$ \\
\hline $\mathrm{R}^{2}$ & & 0.496 & 0.496 & 0.496 & 0.496 & 0.656 & 0.655 & 0.656 & 0.655 & 0.733 & 0.733 & 0.733 & 0.733 \\
\hline
\end{tabular}

